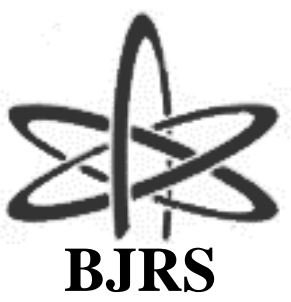

\author{
BRAZILIAN JOURNAL \\ $\mathrm{OF}$ \\ RADIATION SCIENCES \\ 06-01 (2018) 01-15
}

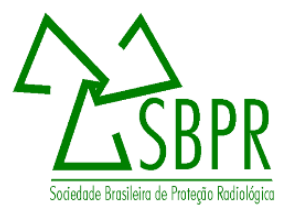

\title{
Deconvolution method to split up X-ray peaks emitted by ${ }^{223} \mathbf{R a}$
}

\author{
R. F. P Simões ${ }^{a b}$; R. L. da Silva ${ }^{a}$; L. V. de Sáa; R. Polednaa ${ }^{a}$ C. J. da Silva ${ }^{a}$ \\ ${ }^{a}$ Instituto de Radioproteção e Dosimetria / Comissão Nacional de Energia Nuclear / LNMRI, 22783-127, Rio de Janei- \\ ro, RJ, Brazil \\ ${ }^{b}$ Instituto Nacional do Câncer José Alencar Gomes da Silva / Física Médica, 20230-130, Rio de Janeiro, RJ, Brazil
}

rafael@fisicomedico.com.br

\begin{abstract}
The Radium-223 $\left.{ }^{223} \mathrm{Ra}\right)$ has being used as a medicine for localized treatment of patients with osteoblastic metastasis originated by prostate cancer resistant of castration or hormone refractory. For a better treatment with this radionuclide, clinical images are one path to turn achievable organ's dosimetry for each patient. The X-rays emitted by ${ }^{223} R a$ demonstrated as the main way to turn the image acquiring feasible. In order to study this X-ray area, deconvolution is necessary to split up the mains X-ray peaks that are measured by a high-purity germanium detector as doublet peaks in a complex region of the spectrum below $100 \mathrm{keV}$. For this, the Colegram ${ }^{\circledR}$ code was applied using the Low Energy X Voigt fitting curve on raw data source from Maestro® software. Results of activity using the deconvolution data from this work were in agreement with values obtained at absolute standardization live-time anticoincidence counting. The Colegram ${ }^{\circledR}$ code demonstrates a powerful tool to aid Maestro to split up the mains overlapped $X$-rays emitted by ${ }^{223}$ Ra.
\end{abstract}

Keywords: X-Ray; Spectrometry, X-Ray Emission; Area Under Curve; ${ }^{223} R a$. 


\section{INTRODUCTION}

Radium-223 ( ${ }^{223} \mathrm{Ra}$ ) was approved to be used as the radiopharmaceutical radium chloride in Brazil since 2015, but the first usage occurred only in January, 2017 (Registry at Health Ministry $\mathrm{n}^{\circ}$ 1.7056.0104). In Unites States of America and European Community the relevant regulatory bodies issued its licenses for use since 2013 (FDA, 2013; EMA/CHMP, 2013). The radiopharmaceutical action in human organism occurs by the mimicking calcium molecule that has a high absorption in bone formation area particularly in osteoblastic metastases (PARKER, 2013; HENRIKSEN, 2002). This radionuclide delivers its main energy by $\alpha$ particles (95\%) (FLUX, 2017) that have a high linear energy transfer (LET) and short range (up to $100 \mu \mathrm{m}$ ) (BRULAND, 2006; KVINNSLAND, 2001). This feature makes it possible to perform a localized treatment demonstrating better results than those by $\beta$ emitters (ATKINS, 1998; BRULAND, 2006; LEWINGTON, 2005). Currently, the focus of this treatment is on patients with metastatic prostate cancer resistant to castration or hormone refractory (BELLMUNT, 2013; PARKER et al, 2013).

The new objective for developing the treatment with this radionuclide is to individualize the protocol according to lesions extension and clinic conditions (FLUX, 2017). In order to address this aim gamma cameras images are an important tool, but the ${ }^{223} \mathrm{Ra}$ emits less than $2 \%$ of $\gamma$ particles providing images that have not presented good quality for quantification (FLUX, 2017). However, the $\mathrm{NaI}(\mathrm{Tl})$ detector shows the most relevant peak of the spectrum at X-ray region that allows images of the patients with a $20 \%$ centered window at $82 \mathrm{keV}$ (FLUX, 2017; PACILIO, 2016). The study of this X-ray region is important for the calibrations and associated corrections to obtain adequate images and to cooperate to the relative radionuclide standardization.

${ }^{223} \mathrm{Ra}$ decay chain, figure 1 , shows five major alpha particles and three high energy beta particles up to the stable ${ }^{207} \mathrm{~Pb}$ that cannot be isolated (KEIGHTLEY, 2015). In addition, the radioisotope halflife is 11.4354(17) days (COLLINS, 2015) and all sons have half-life up to 36.1 minutes, carrying to a secular equilibrium near 6 hours.

Therefore, the aim of this study is to apply a deconvolution method to split up the mains X-rays emitted by ${ }^{223} \mathrm{Ra}$ from data obtained on a spectrometer germanium detector working with a Maestro II software developed by ORTEC@. In order to achieve this goal, the Colegram ${ }^{\circledR}$ code was used employing the low energy $\mathrm{X}$ Voigt fitting profile to define the multiplet components and to extract correct peak areas as part of the deconvolution procedure (DELGADO, 2002), after subtracting the 
background from a region of interest (ROI) of the spectrum corresponding to the main X-rays of ${ }^{223} \mathrm{Ra}$.

Figure 1: Decay chain of ${ }^{223} R a$.

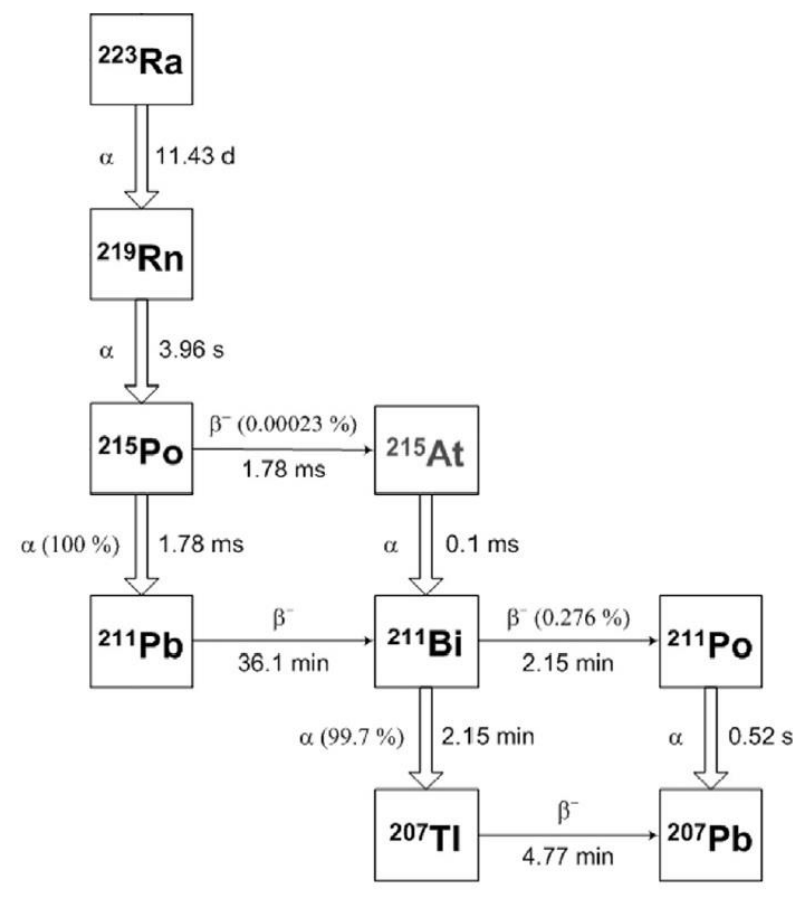

\section{MATERIALS AND METHODS}

Radioactive sources to be measured were prepared diluting ${ }^{223} \mathrm{Ra}$ parent solution from the main source by a factor of $252.50 \pm 0.06$ in an hydrochloric acid $(\mathrm{HCl})$ solution aiming to obtain a small activity and avoiding the detector saturation. The material deposition occurred in a flame-sealed ampoule used by LNMRI (National Metrology Laboratory for Ionizing Radiation) as standard (height mean $2.0 \mathrm{~cm}$ and weight mean $2.6 \mathrm{~g}$ ). The gravimetric method was used to control the active mass in the ampoules using a Mettler Toledo MDX micro analytical balance. The ampoules were centrifuged and the measurements started in germanium detector for a total counting time of $4 \times 10^{5} \mathrm{~s}$ and a dead time of $0.20 \%$. The semiconductor coaxial GeHP (high-purity germanium) n-type detector, brand ORTEC® GWL well-type model 120-15 that means $120 \mathrm{~cm}^{3}$ active volume with 15.5 $\mathrm{mm}$ diameter well tube and $70 \mathrm{~mm}$ diameter endcap has a resolution of $1.49 \%(1.83 \mathrm{keV}$ at $122.56 \mathrm{keV}$ ). Measurements were made for a source detector distance of $40 \mathrm{~cm}$ without using col- 
limator. The detector has been coupled to conventional amplifier and multichannel buffer analyzer and the acquisition software has been the Maestro® II developed by ORTEC® (MAESTRO, 2002). According to the literature the measurement of the impurity by other radionuclides at the production is below the experimental detection limit or negligible (SÁNCHEZ-JIMÉNEZ, 2017) as investigated at this work too.

The secular equilibrium is expected at around 6 hours, because the greater half-life daughter's has 36.1 minutes. The literature suggest $12 \mathrm{~h}$ (KEIGHTLEY, 2015)

Table 1 shows the main X-rays emissions from ${ }^{223}$ Ra and its sons. Although eight peaks can be observed, there are two overlapped regions, the first between 81.07 and $83.78 \mathrm{keV}$, and the others in the second region, as can be seen on figure 2 .

Table 1: The main X-ray emission from ${ }^{223} \mathrm{Ra}(\mathrm{CHECHEV}, 2011)$.

\begin{tabular}{lccc}
\hline Energy [keV] & Source & Intensity (\%) & \#Peak \\
\hline $\mathbf{8 1 . 0 7 0}$ & ${ }^{223} \mathrm{Ra} \mathrm{XK} \alpha 2$ & $14.86(23)$ & 1 \\
$\mathbf{8 3 . 7 8 0}$ & ${ }^{223} \mathrm{Ra} \mathrm{XK} \alpha 1$ & $24.50(4)$ & 2 \\
$\mathbf{9 4 . 2 4 7}$ & ${ }^{223} \mathrm{Ra} \mathrm{XK} \beta 3$ & $8.50(18)$ & 3 \\
$\mathbf{9 4 . 8 6 8}$ & ${ }^{223} \mathrm{Ra} \mathrm{XK} \beta 1$ & $8.50(18)$ & 4 \\
$\mathbf{9 5 . 4 4 9}$ & ${ }^{223} \mathrm{Ra} \mathrm{XK} \beta 5$ & $8.50(18)$ & 5 \\
$\mathbf{9 7 . 4 8 0}$ & ${ }^{223} \mathrm{Ra} \mathrm{XK} \beta 2$ & $2.72(7)$ & 6 \\
$\mathbf{9 7 . 8 5 3}$ & ${ }^{223} \mathrm{Ra} \mathrm{XK} \beta 4$ & $2.72(7)$ & 7 \\
$\mathbf{9 8 . 3 5 7}$ & ${ }^{223} \mathrm{Ra} \mathrm{XKO} \mathrm{XK}_{2,3}$ & $2.72(7)$ & 8 \\
\hline
\end{tabular}

Figure 2: Typical X-ray spectrum from ${ }^{223}$ Ra.

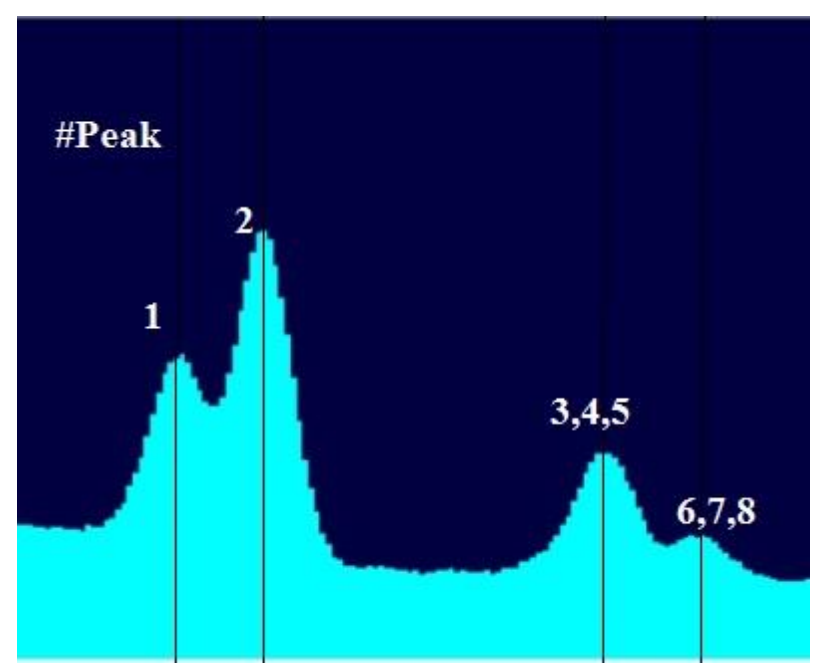


The measurements were performed some days after the ampoules were sealed. The masses of the solution varieties between 2.6 and $2.7 \mathrm{~g}$, while the sources activities varieties between 24.0 and $30.0 \mathrm{kBq}$ at the reference time.

The deconvolution proposed in this study has been initiated with data acquisition system Maestro®, obtaining the original spectrum and total counting per area minus background values (net area). However, the limitation of this software was the inability to dissociate the two peaks groups shown in figure 2 (group 1: peaks 1 and 2, group 2: peaks 3,4,5 and 6,7,8). As alternative, the Colegram ${ }^{\circledR}$ code was used to proceed the deconvolution of each spectrum by fitting the experimental data to an appropriate Voigt profile function for X-rays (DELGADO, 2002; SUORTTI, 1979).

The equation of the fitting curve was the Low Energy X Voigt that can be called as LOWEV(x). It combines the Voigt (Lorentz and Gauss), the low energy tail (T), the discontinuity centered on peak position (S), and discontinuity that is a double-step convolved with the basic Gaussian curve (ST) (LÉPY, 2004). The definition is the equation 1 derived from equations 2, 3, 4 and 5.

$$
\operatorname{LOWEV}(\mathrm{x})=\mathrm{V}(\mathrm{x})+\mathrm{T}(\mathrm{x})+\mathrm{S}(\mathrm{x})+\mathrm{ST}(\mathrm{x})
$$

Where,

$$
V(x)=\int_{-\infty}^{+\infty} L\left(x^{\prime}\right) \cdot G\left(x-x^{\prime}\right) \cdot d x^{\prime}
$$

$L(x), \quad$ Lorentzian function

$G(x), \quad$ Gaussian profile

$$
T(x)=\int_{-\infty}^{x_{0}} A \cdot T \cdot e^{\left(\tau \cdot x^{\prime}\right)} \cdot e^{\left[\frac{-\left(x^{\prime}-x_{0}\right)^{2}}{2 \sigma^{2}}\right]} \cdot d x^{\prime}=A \cdot \frac{T}{2} e^{\left[\left(x-x_{0}\right) \cdot \tau+\frac{\sigma^{2} \tau^{2}}{2}\right]} \cdot \operatorname{erfc}\left[\frac{1}{\sqrt{2}}\left(\frac{\left(x-x_{0}\right)}{\sigma}+\sigma \tau\right)\right]
$$

$\operatorname{erfc}(x), \quad$ error function complementary

$T, \quad$ tail relative amplitude

$\tau, \quad$ exponential slope

$$
\begin{gathered}
\operatorname{erfc}(x)=\frac{2}{\sqrt{\pi}} \int_{x}^{+\infty} \cdot e^{-t^{2}} d t \\
S(x)=\int_{-\infty}^{x_{0}} A \cdot S \cdot e^{\left[\frac{-\left(x^{\prime}-x_{0}\right)^{2}}{2 \sigma^{2}}\right]} \cdot d x^{I}=A \cdot S\left[1-\left(\operatorname{erf}\left(\frac{x-x_{0}}{\sigma \cdot \sqrt{2}}\right)\right)\right]
\end{gathered}
$$

$S$,

step function relative amplitude

$$
S T(x)=\int_{k x_{0}}^{x_{0}} A \cdot S T \cdot e^{\left[\frac{-\left(x^{\prime}-x_{0}\right)^{2}}{2 \sigma^{2}}\right]} \cdot d x^{I}=A \cdot S T \cdot\left[\operatorname{erf}\left(\frac{x-k \cdot x_{0}}{\sigma \cdot \sqrt{2}}\right)-\left(\operatorname{erf}\left(\frac{x-x_{0}}{\sigma \cdot \sqrt{2}}\right)\right)\right]
$$


$\operatorname{erf}(x), \quad$ error function

ST, $\quad$ relative amplitude of the double step

$k, \quad$ low-energy bound of the function

$$
\operatorname{erf}(x)=\frac{2}{\sqrt{\pi}} \int_{0}^{x} \cdot e^{-t^{2}} d t
$$

It should be noted that the parameter "position" is the central energy of the peak, but the germanium detector not always has the perfect calibration for energy resolution creating a small energy lag in the spectrum. It is important to preserve the gap among peaks, ensuring the aligned position with the peak center in the image.

The second adjustable parameter is the "Gauss width", which has to be settled larger for the higher peak. The Tail parameters (tail amplitude, tail slope, step amplitude and truncation (trunc) step amplitude) must be adjusted as the third action. Finally, the amplitude and gamma parameters should be settled.

Although Colegram ${ }^{\circledR}$ code uses the same spectrum data source, it is integrate in a distinct path, resulting in a uncorrelated total counting under each spectrum obtained. This software uses the fitting method to solve non-linear least squares problems with an algorithm Levenberg-Marquardt (LMA) also known as the damped least-squares (DLS) method (MADSEN, 2004).

The live-time anticoincidence counting (LTAC) have been used in order to obtain the activity concentration by an absolute standardization method (DA SILVA, 2008). This activity measurements were used to compare the individual activity measurements obtained by each deconvoluted peak as a quality control check.

The detector has been calibrated using various standard point sources at the same detection conditions: ${ }^{133} \mathrm{Ba}(30.85,35.22,53.16$ and $80.89 \mathrm{keV}),{ }^{152} \mathrm{Eu}(39.90,46.09$ and $121.78 \mathrm{keV}),{ }^{243} \mathrm{Am}$ (43.53 and $74.66 \mathrm{keV}),{ }^{166 m} \mathrm{Ho}(48.80,56.07,80.57$ and $184.00 \mathrm{keV}),{ }^{155} \mathrm{Eu}(86.54$ and $105.31 \mathrm{keV}),{ }^{57} \mathrm{Co}(122.06$ and 136.47$)$ and ${ }^{125} \mathrm{Sb}(176.31 \mathrm{keV})$ and taking into account correction factors for pile-up losses, attenuation and source geometry effects, and $\gamma$ - $\gamma$ and $\gamma$-X summation losses.

The X-rays due to fluorescence of the lead shield appear as low intensity interference lines and do not overlap or significantly influence the lines from ${ }^{223} \mathrm{Ra}$. The highest energy $(\mathrm{Pb}-\mathrm{XK} / \beta 2$ peak) $\mathrm{X}$-ray $\mathrm{Pb}$ emission over than $1.0 \%$ intensity is $87.3 \mathrm{keV}$ with $3.91 \%$ of intensity. The smallest energy gap between this $\mathrm{X}$-ray $\mathrm{Pb}$ and the ${ }^{223} \mathrm{Ra} \mathrm{X}$-ray peaks are more than $3.5 \mathrm{keV}(87.3-83.78 \mathrm{keV})$. The spectrum region at this energy $(87.3 \mathrm{keV})$ is without any apparent peak carrying that is negligi- 
ble, as can be seen in figure 2 and 4. The higher intensities emission, $\mathrm{Pb}-\mathrm{XK}_{\alpha 1}$ and 2 (72.805 and $74.969 \mathrm{keV}$, intensities 27.7 and 46.2\%), (DELGADO, 2002), are in a lower region of energy and do not affect any X-ray region of the ${ }^{223} \mathrm{Ra}$ studied at this work. In addition, the detection environment has its lead shields coated by Cadmium and Cupper in order to decrease the X-rays from Lead shield influence in the region between 70 and $90 \mathrm{keV}$. However, the background correction can eliminate the $\mathrm{Pb}$ fluorescence generated by another natural sources.

\section{RESULTS AND DISCUSSION}

Figure 3 shows the results of the analysis from Maestro® for peaks groups with the resulting total counting and associated uncertain at net area graph parameter.

Figure 3: Total counting in both groups of X ray peaks from ${ }^{223} \mathrm{Ra}$. (a) group 1, (b) group 2.

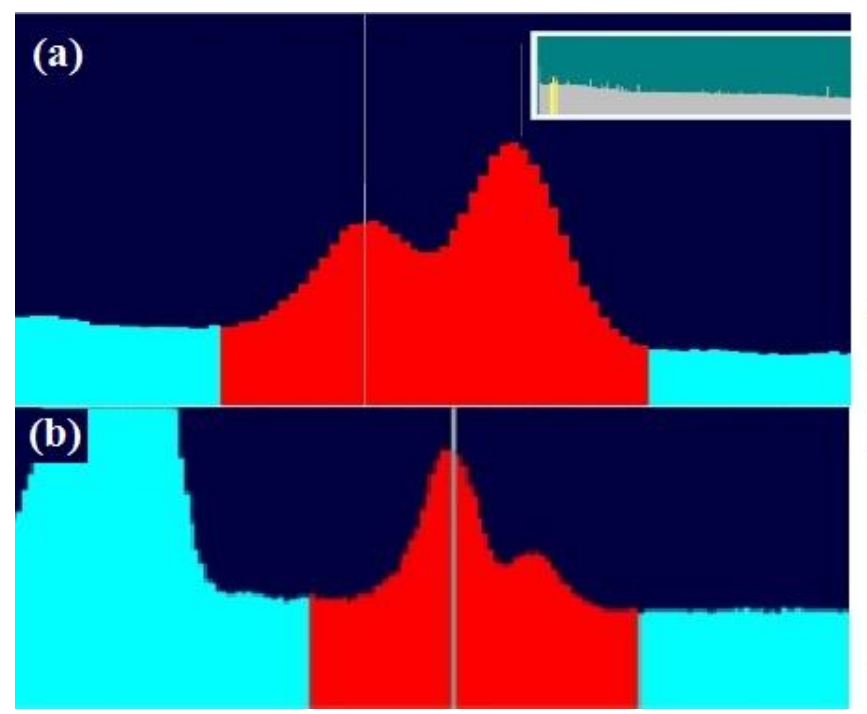

Peak: $447.52=83.98 \mathrm{keV}$

FWHM: 2.18 FW[1/5]M: 5.50

Library: Ra-226 [Radium] at $83.78 ; 300.1 \mathrm{cA}$

Gross Area: 749461

Net Area: $395213 \pm 1606$

Gross/Net Count Rate: $1.82 / 0.96 \mathrm{cps}$

Peak: $506.36=94.92 \mathrm{keV}$

FWHM: 2.28 FW[1/5]M: 5.74

Library: Ra-226 [Radium] at $94.90: 245.1 \mathrm{cA}$

Gross Area: 506029

Net Area: $146278+1887$

Gross/Net Count Rate: $1.23 / 0.36 \mathrm{cps}$

By means of Colegram ${ }^{\circledR}$ it was possible to use the Voigt profile to fitting overlapped X-ray peaks as a sum of components, as demonstrated in figure 4 . 
Figure 4: Representation of the four Voigt fitting profiles (in romaine) and the eight peaks of $\mathrm{X}$-rays from ${ }^{223} \mathrm{Ra}$. Black points is the original counting data source, red is the sum of the fitting and blue is the individual fit curves.

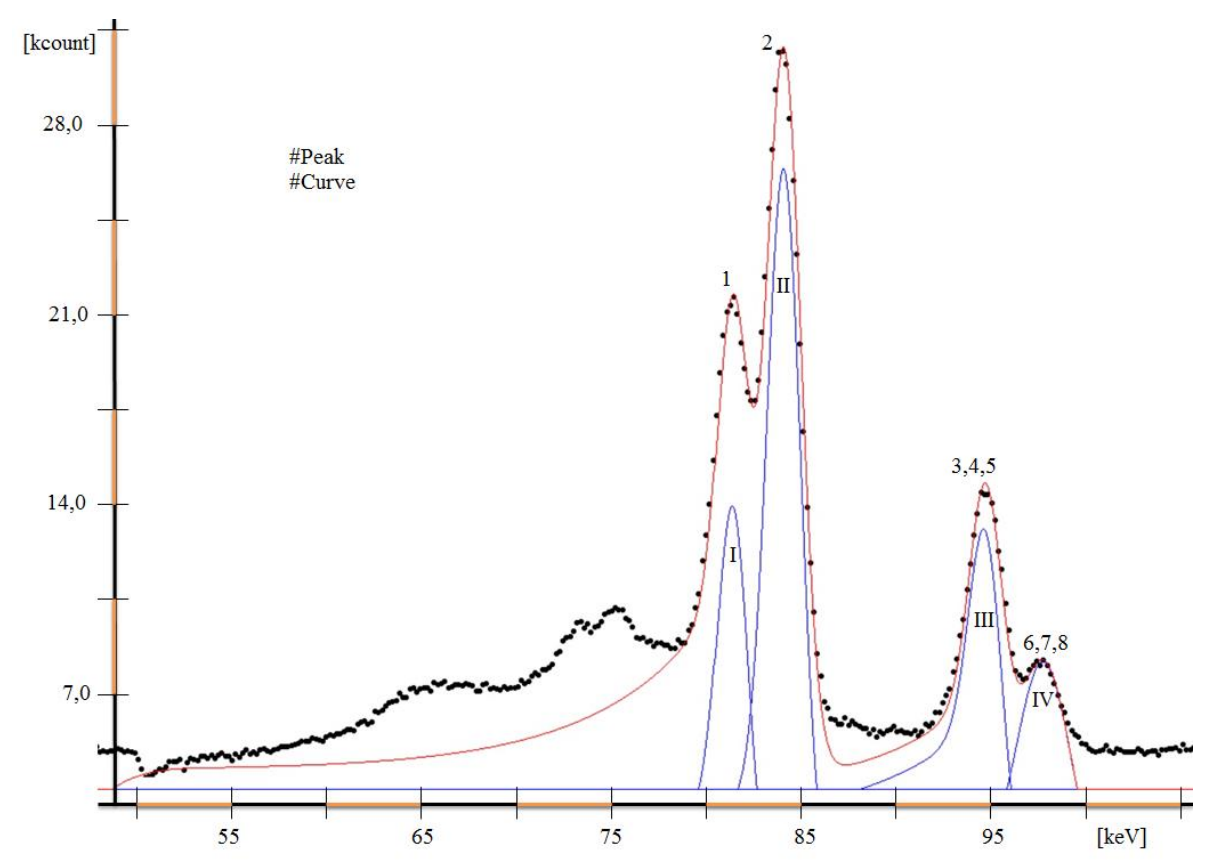

The table 2 shows the Voigt profile parameters used at these fits on group 1 .

Table 2: Low Energy X Voigt profile parameters of fitting at X-ray area for group 1.

\begin{tabular}{lccccccc}
\hline $\begin{array}{c}\text { Energy } \\
{[\mathbf{k e V}]}\end{array}$ & $\begin{array}{c}\text { Voigt } \\
\text { Parameter }\end{array}$ & Value & \#Curve & $\begin{array}{c}\text { Energy } \\
{[\mathbf{k e V}]}\end{array}$ & $\begin{array}{c}\text { Voigt } \\
\text { Parameter }\end{array}$ & Value & \#Curve \\
\hline $\mathbf{8 1 . 0 7 0}$ & Position & 81.44 & I & $\mathbf{8 3 . 7 8 0}$ & Position & 84.15 & II \\
& Amplitude & 12550 & I & & Amplitude & 24550 & II \\
& Gauss width & 0.78 & I & Gauss width & 0.88 & II \\
& Gamma & $9 \times 10^{-2}$ & I & Gamma & $9 \times 10^{-2}$ & II \\
& Tail amplitude & 0.28 & I & Tail amplitude & 0.15 & II \\
& Tail slope & 0.165 & I & Tail slope & 0.165 & II \\
& Step amplitude & $3 \times 10^{-2}$ & I & Step amplitude & $3 \times 10^{-2}$ & II \\
& $\begin{array}{c}\text { Trunc Step } \\
\text { amplitude }\end{array}$ & $5 \times 10^{-3}$ & I & Trunc Step & $5 \times 10^{-3}$ & II \\
& & & amplitude & &
\end{tabular}

For group 1, the highest peak (number 2 as fig.2) is the most energetic and due to the tail, always on the left side of the Low Energy X Voigt curve, influences considerable at the counting of the 
peak 1. On the other hand, if the most energetic peak has the lowest amplitude counting, the tail does not overlap the peak area and the phenomenon will not be repeated in this hypothetic case. The table 3 shows the input data of deconvolution of the six X-ray peaks.

Table 3: Low Energy X Voigt curve parameters of fitting at X-ray area group 2.

\begin{tabular}{lccccccc}
\hline $\begin{array}{c}\text { Energy } \\
{[\mathbf{k e V}]}\end{array}$ & $\begin{array}{c}\text { Voigt } \\
\text { Parameter }\end{array}$ & Value & \#Curve & $\begin{array}{c}\text { Energy } \\
{[\mathbf{k e V}]}\end{array}$ & $\begin{array}{c}\text { Voigt } \\
\text { Parameter }\end{array}$ & Value & \#Curve \\
\hline $\mathbf{9 4 . 2 4 7}$ & Position & 95.01 & III & $\mathbf{9 7 . 4 8 0}$ & Position & 98.05 & IV \\
$\mathbf{9 4 . 8 6 8}$ & Amplitude & 10000 & III & $\mathbf{9 7 . 8 5 3}$ & Amplitude & 8100 & IV \\
$\mathbf{9 5 . 4 4 9}$ & Gauss width & 0.87 & III & $\mathbf{9 8 . 3 5 7}$ & Gauss width & 1.45 & IV \\
& Gamma & $6 \times 10^{-2}$ & III & & Gamma & $6 \times 10^{-2}$ & IV \\
& Tail amplitude & 0.4 & III & & Tail amplitude & $1 \times 10^{-2}$ & IV \\
& Tail slope & 0.15 & III & & Tail slope & $2 \times 10^{-2}$ & IV \\
& Step amplitude & 0.15 & III & Step amplitude & $1 \times 10^{-2}$ & IV \\
& Trunc Step am- & 0.10 & III & & Trunc Step & $9 \times 10^{-2}$ & IV \\
& plitude & & & amplitude & & \\
\hline
\end{tabular}

Following the same fitting methodology, using a unique Low Energy X Voigt profile to represents three X-rays peaks probabilities, it was also suitable. These three overlapped X-rays peaks leads to the Gauss width being to be larger than the adjustment used on curve 1 and 2 .

The tail also has to be personalized for each three peaks group (curve III and IV). The fitting parameters should not have same values because the gaps between the three energy peaks are not the same in each group. Thereby, the tail parameters of curve III has to be distinct of the same for the curve IV.

Table 4 shows the results of total counting for each fitting curve obtained in Colegram ${ }^{\circledR}$ code with the parameters listed on tables 2 and 3 using equation 1.

Moreover, it is possible to extract the influence of each fitting curve under the doubled curve. For this purpose, the individual total counting under each fitting profile at Colegram ${ }^{\circledR}$ output parameters ratio sum of both can extract the representative percentage of each individual area under the curve. As this output Colegram ${ }^{\circledR}$ parameters have no normalization with Maestro® output counting, the percentage can normalize the transposition between the software arbitrary counting methods. Multiplying the percentage obtained on Colegram ${ }^{\circledR}$ to the total net counting for the doublet 
peak can split up the contribution counting of each individual peak from the doublet in terms of Maestro® arbitrary counting method. The same can be done with the uncertain. The resumed parameters of the deconvoluted peaks are shown in table 4 .

Table 4: Results from Colegram ${ }^{\circledR}$ for I, II, III and IV fitting curves and their respectively representative percentage with the deconvoluted results and associated uncertainties.

\begin{tabular}{lccccc}
\hline Curve & $\begin{array}{c}\text { Colegram }{ }^{\text {Total }} \\
\text { Counting }\end{array}$ & $\begin{array}{c}\text { Representative } \\
\text { from total } \\
\text { counting [\%] }\end{array}$ & $\begin{array}{c}\text { Maestro® } \\
\text { Total Net } \\
\text { Counting* }\end{array}$ & $\begin{array}{c}\text { Total Counting } \\
\text { deconvoluted } \\
\text { (Maestro®) }\end{array}$ & $\begin{array}{c}\text { Uncertain } \\
\text { deconvoluted } \\
\text { (Maestro®) }\end{array}$ \\
\hline Curve I & 424740.5 & 35.5 & $395213 \pm 1606$ & 140301.7 & 570.1 \\
Curve II & 771622.6 & 64.5 & & 254914.3 & 1035.9 \\
Curve III & 414639.0 & 22.6 & $146278 \pm 1887$ & 113219.2 & 426.5 \\
Curve IV & 1421418.0 & 77.4 & & & 1460.5 \\
\hline
\end{tabular}

The results from LTAC (activity at reference date) are shown in table 5 with the comparative with the activities obtained from the spectroscopy individual area deconvoluted at this work. The uncertainties are considering $\mathrm{k}=1$.

Table 5: Activity comparison of ${ }^{223}$ Ra.

\begin{tabular}{lcccc}
\hline \multicolumn{1}{c}{ Method } & $\begin{array}{c}\text { Energy } \\
{[\mathbf{k e V}]}\end{array}$ & $\begin{array}{c}\text { Intensity } \\
{[\%]}\end{array}$ & $\begin{array}{c}\text { Activity } \\
{[\mathbf{k B q} / \mathbf{g}]}\end{array}$ & $\begin{array}{c}\Delta \\
{[\%]}\end{array}$ \\
\hline LTAC & all & - & $1069.88 \pm 0.12$ & - \\
Spectrometry $\gamma$ & 81.070 & $14.86(23)$ & $1068.89 \pm 9.05$ & $-0.09 \%$ \\
Spectrometry $\gamma$ & 83.780 & $24.50(4)$ & $1106.16 \pm 11.98$ & $3.28 \%$ \\
Spectrometry $\gamma$ & 94.247 & $8.50(18)$ & $1119.51 \pm 13.92$ & $4.43 \%$ \\
Spectrometry $\gamma$ & 94.868 & $8.50(18)$ & $1107.64 \pm 13.78$ & $3.41 \%$ \\
Spectrometry $\gamma$ & 95.449 & $8.50(18)$ & $1096.76 \pm 15.82$ & $2.45 \%$ \\
Spectrometry $\gamma$ & 97.480 & $2.72(7)$ & $1072.85 \pm 15.48$ & $0.28 \%$ \\
Spectrometry $\gamma$ & 97.853 & $2.72(7)$ & $1066.62 \pm 15.39$ & $-0.31 \%$ \\
Spectrometry $\gamma$ & 98.357 & $2.72(7)$ & $1058.19 \pm 7.32$ & $-1.10 \%$ \\
\hline
\end{tabular}


The figure 5 shown the data from table 5 .

Figure 5: Activity comparison of ${ }^{223} \mathrm{Ra}$.

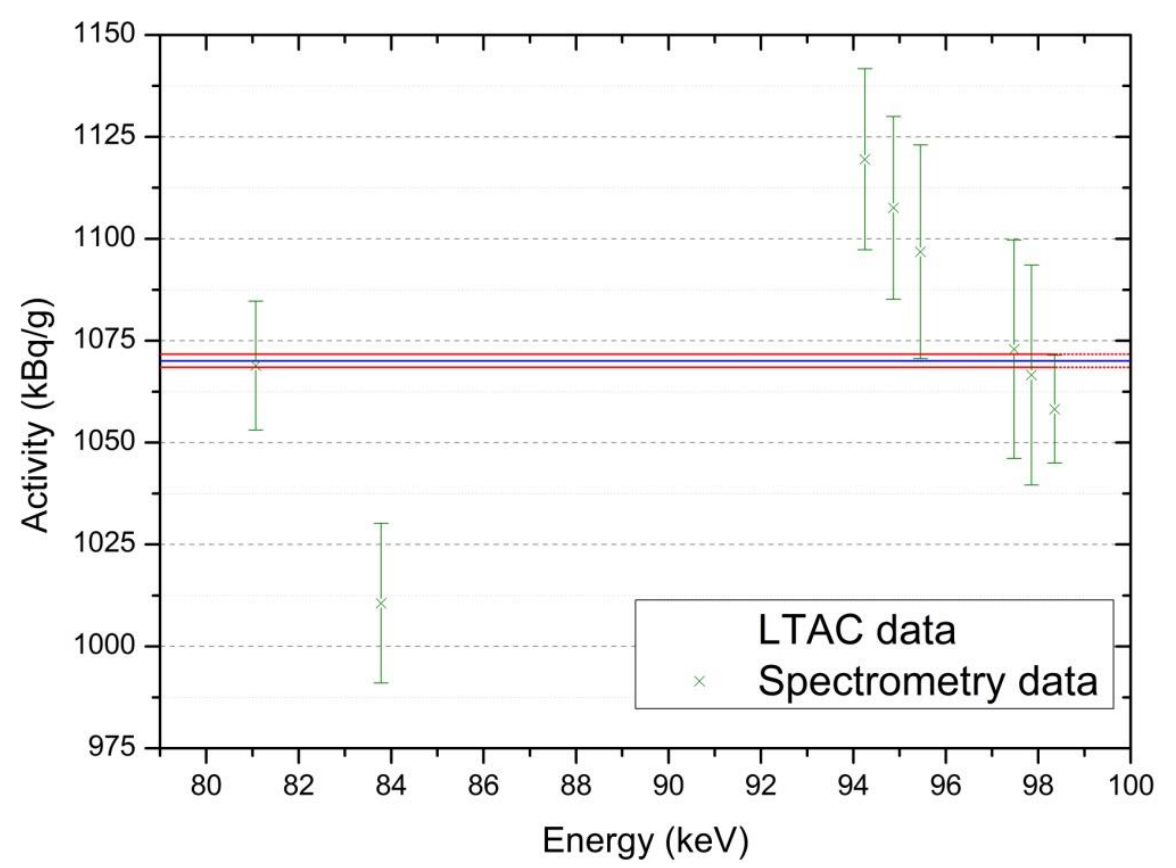

The peaks out of the alignment of the mean activity from LTAC method suggest that a new gamma probabilities may be established. The mean activity obtained in spectrometry method in 23 points was 1067.2 \pm 21.50 that is statically equivalent of the activity of LTAC results (1069.9 \pm 1.6$)$.

If the peak 2 received more percentage of counting from deconvolution method, the peak 1 will have less counting, so they will be both out of confirmatory activity line. It suggest that the peak 2 emission probability should be adjusted.

The peaks 3, 4 and 5, are all over than the confirmatory activity line, so they should be revised by the emission probability. As can be observed they are not aligned, it suggest that they have not the same emission probability as described at literature (CHECHEV, 2011).

The peaks 1, 5, 6, 7 and 8 concerned an activity value statistically equivalent of the LTAC measurements.

There are not outliers by the Dixon's hypothesis test.

\section{CONCLUSION}

The Colegram ${ }^{\circledR}$ code demonstrates a powerful tool to help the data acquisition analysis system to split up the mains overlapped X-rays emitted by ${ }^{223} \mathrm{Ra}$. 
Furthermore, this study makes viable standardization in a relative method from the X-rays zone complex of this isotope of radium.

\section{ACKNOWLEDGMENT}

The authors would like to thank Johnny de A. Rangel and Eduardo V. de Veras for their skillful assistance in source preparation. We would like to thank the staff at Bayer® for the supply of the

${ }^{223} \mathrm{Ra}$ source used at the whole study.

\section{REFERENCES}

ATKINS, H. L. Overview of nuclides for bone pain palliation. Applied radiation and isotopes, v. 49, n. 4, p. 277-283, 1998.

BELLMUNT, J. Tackling the bone with alpha emitters in metastatic castration-resistant prostate cancer patients. European urology, v. 63, n. 2, p. 198-200, 2013.

BRULAND, $\varnothing$. S. et al. High-linear energy transfer irradiation targeted to skeletal metastases by the $\alpha$-emitter ${ }^{223} \mathrm{Ra}$ : adjuvant or alternative to conventional modalities?. Clinical cancer research, v. 12, n. 20, p. 6250s-6257s, 2006.

CHECHEV, V. P., et al. Table of radionuclides (Vol. 6-A= 22 to 242). Monographie BIPM-5, Bureau International des Poids et Mesures, Sèvres, p.85-89, 2011.

COLLINS, S. M. et al. Direct measurement of the half-life of ${ }^{223}$ Ra. Applied Radiation and Isotopes, v. 99, p. 46-53, 2015.

DA SILVA, C. J. et al. Standardization of ${ }^{241} \mathrm{Am},{ }^{124} \mathrm{Sb}$ and ${ }^{131} \mathrm{I}$ by live-timed anti-coincidence counting with extending dead time. Applied Radiation and Isotopes, v. 66, n. 6, p. 886-889, 2008. 
DELGADO, J. U.; MOREL, J.; ETCHEVERRY, M. Measurements of photon emission probabilities from the decay of ${ }^{226} \mathrm{Ra}$ and daughters. Applied Radiation and Isotopes, v. 56, n. 1, p. 137$143,2002$.

EMA/CHMP - European medicines Agency/Committee for Medicinal Products for Human Use, Document EMA/CHMP/411215/2013, Summary of Opinion, Initial Authorization. 19 September 2013, Available at:

<http://www.ema.europa.eu/docs/en_GB/document_library/Summary_of_opinion__Initial_authorisation/human/002653/WC500150073.pdf>. Last accessed: 15 sept. 2017.

FDA - Food and Drug Administration. FDA approves new drug for advanced prostate cancer. 2013, Available at:

<https://www.accessdata.fda.gov/drugsatfda_docs/appletter/2013/203971Orig1s000ltr.pdf> Last accessed: 15 sept. 2017.

FLUX, G. D. Imaging and dosimetry for radium-223: the potential for personalized treatment. The British Journal of Radiology, v. 90, n. 0, p. 20160748, 2017.

HENRIKSEN, G. et al. Significant antitumor effect from bone-seeking, $\alpha$-particle-emitting 223Ra demonstrated in an experimental skeletal metastases model. Cancer research, v. 62, n. 11, p. 3120$3125,2002$.

KEIGHTLEY, J. et al. Standardization of ${ }^{223} \mathrm{Ra}$ by liquid scintillation counting techniques and comparison with secondary measurements. Applied Radiation and Isotopes, v. 95, p. 114-121, 2015.

KVINNSLAND, Y.; SKRETTING, A.; BRULAND, Ø. S. Radionuclide therapy with bone-seeking compounds: Monte Carlo calculations of dose-volume histograms for bone marrow in trabecular bone. Physics in medicine and biology, v. 46, n. 4, p. 1149, 2001. 
LÉPY, M.C. Presentation of the COLEGRAM software. Note Technique LNHB/04/26, Saclay, France, 2004.

LEWINGTON, V. J. Bone-seeking radionuclides for therapy. Journal of nuclear medicine, v. 46, n. 1 suppl, p. 38S-47S, 2005.

MADSEN, K., NIELSEN, H. B. and TINGLEFF, O. Methods for non-linear least squares problems. 2004.p.24-28.

MAESTRO, I. I. Software Operator's Manual. Maestro for Windows. Version 5.33. EG\&G. ORTEC, 2002.

PACILIO, M. et al. A case report of image-based dosimetry of bone metastases with Alpharadin $\left({ }^{223} \mathrm{Ra}\right.$-dichloride) therapy: inter-fraction variability of absorbed dose and follow-up. Annals of nuclear medicine, v. 30, n. 2, p. 163-168, 2016.

PARKER, C. et al. Alpha emitter radium-223 and survival in metastatic prostate cancer. New England Journal of Medicine, v. 369, n. 3, p. 213-223, 2013.

SÁNCHEZ-JIMÉNEZ, J. et al. 223 Ra-dichloride spectrometric characterization: Searching for the presence of long-lived isotopes with radiological protection implications. Physica Medica, v. 35, p. 97-101, 2017. 
SUORTTI, P.; AHTEE, M.; UNONIUS, L. Voigt function fit of X-ray and neutron powder diffraction profiles. Journal of Applied Crystallography, v. 12, n. 4, p. 365-369, 1979. 